\title{
CLIL as a significant component of educational process organization
}

\author{
O. L. Shcherbakova, S. S. Nikiforchuk \\ V.O. Sukhomlynsky National University, Ukraine \\ Corresponding author. E-mail: djmangouste@gmail.com
}

Paper received 18.05.20; Accepted for publication 10.06.20.

\section{https://doi.org/10.31174/SEND-HS2020-230VIII38-15}

\begin{abstract}
The article is devoted to the problem of the use of Content and language integrated learning approach which is widely used in teaching practice Attention is focused on objectives of CLIL, explore its methods, advantages and disadvantages, perspectives, and the implementation of this approach as a significant component of educational process organization. The article points to the necessity of the use of CLIL approach at higher educational institutions for development of students' professional skills. Such method diversifies teach-ing tools and forms of classroom teaching and learning and consequently increases students' motivation.

Keywords: content and language integrated learning (CLIL), communicative competence, vocational training, students' motivation, language competences, implementation of CLIL, learning language.
\end{abstract}

Problem statement. CLIL (Content and Language Integrated Learning) is a term created in 1994 by David Marsh and Anne Maljers as a methodology similar to language immersion and content-based instruction. It's an approach for learning content through an additional lan-guage, thus teaching both the subject and the language. CLIL is a new didactic approach to teaching subjects integrating two features - linguistic and factual. There are two kinds of CLIL: the so-called hard CLIL and soft CLIL methods. Hard CLIL means that the subject or subject curriculum is taught in a foreign language. How-ever, the main lesson objective is the content objective, not the language, while in the so-called soft CLIL form, the content of the subject is subordinate to the language goal. A higher emphasis is put on learning the language. Briefly said, the CLIL method employs the language to pass on the knowledge from a different subject.

CLIL fits well with powerful language learning theories and, in general, with theories that acknowledge the role that language plays in all learning. In this respect, Halli-day presents a complex perspective of learning in general, and language learning in particular, which consists of a continuum of three main interdependent processes: learning language, learning through language and learning about language. The interdependence and structural continuity of the learning processes thus is explained by the fact that all "learning is learning to mean, and to expand one's meaning potential" [11, p.113].

Indeed, schools are institutions where teaching languages, developing educated ways of using them, and focusing on the use of language are primary interdependent goals. However, schooling, with its traditional segmentation of the syllabus in school subjects with clearly drawn boundaries, often overlooks the continuity among the axes signalled by Halliday, and their corresponding learning goals. The result of this is that teachers of sub-jects labelled commonly approach language lean-ing/teaching through the strategy of learning/teaching about language whereas teachers of subjects labelled 'other-than-language', such as Science, History or Music, expect students to absorb the particular ways of discipli-nary literacies simply by teaching through language, with little attention paid to the ways in which language is em-ployed in meaning-making within the field. Halliday puts it very simply saying that in research and in classroom practice this relationship is frequently ignored. He states that in subject matter learning we overlook the role of language as a medium of learning, in language learning we overlook the fact that content is being communicated. Content and Language Integrated learning (CLIL) is a plurilingual approach to learning and teaching in formal contexts that creates a space which naturally leads to the implementation of Halliday's triadic perspective on (lan-guage) learning by placing the language learning continu-um at its very heart [11].

Analysis of researches and publications. The atten-tion to the problem of the use of Content and Language Integrated learning in educational process was given by such scholars as M.Halliday, M.Wozniak, P.Bertaux, D.Banegas, D.Coyle, P.Hood, D.Marsh and others. The works of J.Harmer, M.Druzhinina, F.Temirova, D. Westall, N.Belenkova, A.Atabekova quite profoundly analyze and concretize the essence of CLIL of its usage in the process of professional training of specialists in higher education establishments. As the expansion of multilingualism contributes to effective integration of Europe, the European Union is deeply concerned with foreign language teaching and encourages the development of innovative teaching methods. CLIL has become a key issue in European educational considerations in recent years and both the European Union and the Coun-cil of Europe are actively involved in promoting the no-tion of content and language integrated learning. The organizations encourage initiatives, such as seminars, conferences or Internet networks that spread information about best practices in CLIL.

In 1985 the European Council proclaimed a resolution presenting the main principles concerning the European educational policy, including foreign languages. It stated that the knowledge of foreign languages plays a key role in the European integration. The member states declared to respect linguistic diversity as a basis of cultural heritage of Europe. Teaching of practical foreign language skills from an early age was emphasised. The pupils should be enabled to learn at least two foreign languages. In order to implement the premises of the resolution, new measures of language teaching were needed. Teaching content through the medium of a foreign language served the purpose as it developed not only fluency in a foreign language, but also practical and intercultural competence. Depending on national regulations, from one to a few subjects are taught through a medium of a foreign lan-guage. The choice of 
subject is determined by the regional diversification; CLIL is used mainly in the humanities and science subjects.

Other differences in CLIL provision observed in European countries are: qualification of the teaching staff, the access to didactic materials, the assessment of students' performance, and the amount of target language used. Content and language integrated learning is more demanding than traditional approach to education, there-fore its implementation requires coordination on the school and government level. The most frequent prob-lems observed by the Eurydice in European schools were: deficiency of adequately qualified teaching staff, inade-quate educational law and insufficient material and fi-nancial support (Eurydice, 2006).The teachers notice the shortage of training that would introduce the methodolo-gy of content and language integrated learning, hence problems with recruiting teaching staff possessing the appropriate qualifications. Moreover, the educators no-tice difficulties with finding appropriate teaching materi-als that would comply with the national curricula and suit the needs of content and language integrated learning. Apart from the didactic constraints, problems of legal and financial nature can be noticed. There is a need across Europe to formulate clear educational law that would promote and, in some cases, legalize teaching subjects through a foreign language. Some countries indicate that introduction, implementation and development of CLIL programmes involve high expenses on both local and state level [10].

The purpose of the article: on the basis of scientific literature to to highlight objectives of CLIL, explore its methods, advantages and disadvantages, perspectives, and regard the implementation of this approach as a sig-nificant component of educational process organization.

Exposition of the basic material. There are several ways CLIL could be defined; however, Temirova and Westall remind us that CLIL is a pedagogical approach in which language and subject area content are learnt in combination. The generic term CLIL describes any learning activity where language is used as a tool to develop new learning from a subject area or theme. When institu-tions decide on implementing CLIL, there are several as-pects that need to be taken into account, among them motivation, which plays a crucial part in this process. Darn posits that "natural use of language can boost a learner's motivation towards learning languages [....] Language is learnt more successfully when the learner has the opportunity to gain subject knowledge at the same time" [14, p.4].

Coyle, Hood and Marsh discussed a combination of content, cognition, communication, and culture (the 4Cs framework), allowing students to not only experience significant learning but to gain a wider vision of the world in which they live. Therefore, it is no surprise that using an approach such as CLIL can bring about many positive changes in the classroom which do not come easy in terms of implementation [8].

Regardless of the context and environment, implementation of CLIL does not come easy because of many factors such as time tables, qualified teachers, budget, resources and others. One of such factors is a lack of op-portunities of teachers to collaborate in the curriculum. Thus, Woźniak claims that two types of teachers (lan-guage teachers and content teachers) teachers require further training on collaboration in order to know how this process should be developed and improved to support and maintain an effective integration of both content and language. McDougald states that content specialists should be given more opportunities in connection with language learning and teaching in order to successfully promote students' language skills. Teachers are much too concerned with trying to deliver individual results, without considering the whole or the overall learning process. Ruiz Garrido and Gómez also remind us that all teacher train-ing and collaboration activities within a given institution should be part of a global institutional strategy with clear objectives and recognition of the effort made by the par-ties involved. Cenoz and Genoz, Genesee, and Gorter have also insisted that institutional goals are needed so that success across the board can be accomplished [15].

Science is all about experimenting, looking for new ways of doing things, coming up with new results - or even different results for that matter. However, when the experimentation has concluded, there should be some type of documentation of the lessons learned so that oth-ers can pick up and have more success.

Unfortunately, there has been little research on CLIL covering all aspects of implementation. However, there have been dozens of isolated CLIL endeavors focusing on issues such as teacher training. In recent studies the attitudes, motivation, and receptive vocabulary of two groups of students, one in a regular English class and the other in a CLIL class were evaluat-ed. As has also been found in other studies, the students in the CLIL group scored higher in receptive vocabulary, apparently due to motivation; nevertheless, it was also found that CLIL was perceived as being of little or very little help. Thus, it is obvious that the negative attitude towards CLIL may have to do with the fact that the im-plementation thus far was somewhat irregular in the school and this may have had a negative effect on the students' attitude [13].

There is one a reason that working together, in teams, and collaborating with one another has been common a response to overcoming the particular obstacle of lack of proper teacher-training programs. Yet, on another note, teacher-training programs attempting to cater to the needs of CLIL approaches are often insufficient due to quantity and complexity of the variables that affect CLIL programs. For example, amongst the variable that need to be considered when planning a teacher-training program are context, evaluation of both language and content, type of educational institutional (preschool, pri-mary, secondary or even higher education), hours, model or type of program, language used, metacognitive strate-gies, or even the teacher's prior experience [13].

Moreover, Arno-Macia and Mancho-Bares discuss the need to train content lecturers to develop graduates' proficiency in English, once again increasing communicative competences needs. Considering that CLIL is not easy to put into practice, it is key that a strong collaboration among subject teachers and language teachers; this is partially because these types of classes can be most ef-fective when there is a large range of activities. By work-ing together, training both content and language teachers to collaborate in developing and implementing the most appropriate kinds of tasks for their learners, CLIL out-comes could be much more successful [1]. 
In general, CLIL method is supposed to develop some necessary competences in the current globalized world, such as

- A multicultural approach is to become more and more common in the current world and to live within one country with speakers of other languages with a different cultural background may be soon considered as a matter of fact. This approach develops communication across cultures.

- Students are offered real-life situations where they are to use English as a communication means and this makes them raise their awareness as to how the language itself is used, as well as cross-cultural awareness. The learners develop their immediate speaking skills with an emphasis on fluency.

- A diversity of methods and materials prepares students to deal with people from different cultural, lan-guage, and social backgrounds and to perceive the differ-ences as a part of other culture that enriches them. It en-hances teamwork and helps individuals to find their roles in a team. The use of various kinds of materials helps to develop learners' flexibility.

- Excellent materials offer up-to-date study resources available not only for teachers but also for students in various forms. These materials develop learners' orientation in online and printed information. Students are exposed to written and oral resources and, due to that fact, they become aware of different idioms, sayings and fixed expressions used in all sorts of situations.

- Learners have the opportunity to learn about their learning styles (e.g. visual, kinaesthetic, auditory) within these kinds of activities and gradually work on develop-ing skills.

- Students develop their skill to learn the target subject through a language (which is not their mother tongue).

Another consequential feature is the emphasis on ac-tive participation of the learners. The teacher's role in the classroom is more concentrated on monitoring and assisting. This way enables the students to remember and experience more as their curiosity is boosted up by certain types of activities (e.g. brainstorming, mingling and matching, filling in the rest of a sentence or a paragraph, etc.).

CLIL as a teaching method has its advantages but it also has some drawbacks when compared with other approaches. As for the positive aspects the following ones can be named: learning enhances critical thinking of stu-dents; the learning process is based on real life situations; leaning is based on teamwork (in some countries based on projects); raising the intercultural awareness of both students and teachers; increasing employability; breaking various kinds of prejudice and fear of travelling outside the home country; acquiring communicative skills and patterns.

Possible negative aspectscan be a high level of time consumption for material preparation; students/teachers do not have the relevant level of foreign language knowledge; not enough information on the CLIL meth-od; lack of motivation to use the CLIL approach; reluc-tance of using the method;

A big area of research relates to CLIL teachers, teacher competences and teacher-related issues. Benagas observed that most problems found in the first stages of CLIL implementation are: theoretical assumptions, class-room methodology and integrated methodology imple- mentation. Teachers and trainers need to build a bridge between theory and practice. Benagas also points out to the huge impact the change of roles of teachers has on their self-perception, resulting in confusion and uncertain-ty. The scientist concludes that CLIL should be a negoti-ated enterprise amongst administrators, curriculum plan-ners and teachers. So collaboration is seen as vital not only on teacher to teacher basis, but also should include administration and curriculum developers, therefore collaboration on different levels presupposes the key to success. Bebagas states that understanding of CLIL methodology can compensate the lack of teacher's language competencies in CLIL classroom. CLIL teachers' ICT competences and attitudes towards application of ICT were studed in various contexts, including CLIL classes. The study revealed the teachers' largely positive attitude to the application of ICT in CLIL classroom, stressing the following advantages: use of authentic resources, possibility to differentiate tasks and the teaching process, motivation and organization of students' individual work [3].

Bertaux researched success factors of CLIL implementation in tertiary education and constructed a conceptual model of 3C's, in which three factors: the conditions, the commitment, and competencies, accounted for successful CLIL implementation. He stressed that especially commitment and competences (linguistic, didactic and multi-cultural) of the faculty determine the success or failure of the English-based curriculum. By commitment she meant teachers' willingness to make sacrifices, to invest extra time and energy if necessary; it also means affective and psychological attachment to the target of commitment, i.e. teachers' mostly positive attitude to the innovation and belief in what they do. Bertaux states that competence framework seems more detailed, but at the same time more difficult to apply because of the absence of a clear distinction between competences required for language teachers or for subject teachers, for beginner teachers and for experienced teachers [5].

Content and language integrated learning (CLIL) approach is widely used in teaching practice at higher educational institutions and is much supported by the European Commission. Unfortunately, there has been little research on CLIL implementation in Ukraine covering all aspects This approach is focused mostly on studying the main subjects in a foreign language learnt by the stu-dents. Mostly while learning a foreign language in a nonlinguistic higher educational institution implies a real-life setting which includes the situations closely connected with the students' professional interests.

State educational standards of higher education points out that BA graduates must have a number of generic and professional competences, and as far as a foreign language is concerned they must have sufficient skills to communicate in a professional domain in a foreign language. This communication can occur both orally and in a written form and naturally all the skills should be developed systematically and regularly.

Professional communication as a process of interpersonal relations is exercised as the following communicative needs of a specialist: realization of a collective professional activity; exchange of data, information, and research views;development of common strategy of interaction in the professional field etc. 
All issues mentioned above are essential both for an individual and for a group of specialists united on the basis of their profession. Professional communication is realized in professional setting due to the communicative function of the language.

Educators and researchers emphasize that the goal of a foreign language teaching in linguistic faculties and universities is to develop communicative skills that will assist graduates to realize professional contacts in a foreign language in different situations in English.

Besides learning English in the frames of CLIL this approach helps students to develop the specific way of thinking and to be ready to perform their professional duties and responsibilities.

Professional duties and responsibilities of our students can include not just speaking but teaching English as a foreign language. A future teacher should deal with different age of children, taking into consideration different forms and approaches. Moreover graduates of a higher educational institution in the domain of secondary education should always work in accordance with methodology; be aware of teaching methods, lesson design, control and assess his/her professional activity and its outcomes, realize the importance of regular professional selfdevelopment; be ready to get new information; respect moral and cultural values as well as opinions of other people; be hardworking and responsible; reserved and decisive (Belenkova, 2012)

The experience of Foreign Languages Department of V.O Suhomlynsky National University shows that BA students succeed in such disciplines as Practical course of English language and Methodolody of teaching English due to CLIL approach.

At the practical course of English students try to develop everything mentioned above and consequently improve not only foreign language skills but special skills as well. They participate in international conferences and moots, submitting research papers in English, interpreting traineeships etc. To reach the goal of each mentioned above activity students should take into account the ad-equate vocabulary items and grammar structures. Speak-ing about special component of the activity the emphasis is made on the transfer of theoretical special knowledge into the area of the practical solution of a task, and af-terwards the transfer of the skills developed from one situation into another; and afterward further transfer of data from the particular situation into a general pattern. Here the correlation of the special subject from the core curriculum of the learners and their personal experience occurs.

Analyzing the close connection of language and spe-cial vocational training in the frames of CLIL in a nonlinguistic higher educational institution we agree with the statement that the quality of language education depends on the quality of vocational education [9]. The opposite contention can also be considered as valid and essential, inter alia the quality of vocational education depends on the quality of language education. Consequently to en-hance special competences of teachers-to-be language skills and communicative competences of the students should be constantly cultivated. For this purpose definite tasks and assignments developing both foreign language skills and special vocational skills should be designed and realized in teaching practice.
The issue of CLIL and foreign language teaching integration is immense; it can be examined from various points of view in teaching listening, speaking, reading, writing etc. This paper shows some aspects of BA stu-dents' teaching speaking skills. Discussing some issues of different teaching methods and approaches in a foreign language teachers-to-be improve their knowledge, skills and know-how of their profession. 'They also develop their foreign language speaking skills.

CLIL approach can be integrated into teaching prac-tice from the very beginning of vocational training at University. We suppose that this integration can be successful if the students' language acquisition level is B-1or higher according to the Common European References. At this level learners "can understand the main points of clear standard input on familiar matters regularly encoun-tered in work... etc..., can produce simple connected text on topics which are familiar or of personal interest. Can describe experiences and events ... and briefly give reasons and explanations for opinions and plans" [7. p. 24].

Though the first year students do not have sufficient vocational knowledge and skills but we can suppose that their interest in their profession will help to cope with this problem.

Communicative and problem solving tasks, project mak-ing activity will enhance learners' foreign language speak-ing. The theoretical background of the communicative task application into teaching practice and the examples of such assignments are provided by A. Atabekova and N. Belenkova [2].

Foreign educators and researchers in teaching English as a foreign language pay much attention to the ways of how to improve students' speaking skills. First of all learners should know an appropriate number of vocabulary items, grammar patterns and some expressive means (e.g. speed of the utterance) to support the debate and participate in a discussion. Students should know these expressions and must be taught how to use them in professional setting [12].

Success in speakers' productivity also depends on their foreign language processing skills i.e. speakers must transform the information in their heads and put it in a comprehensible form from the point of view of the language and the meaning. Language processing involves word and phrase extraction from the speaker's memory and then the word and phrase assembly into the correct sequences. Foreign language processing skills development is a matter of foreign language teaching and the corresponding speaking activities should be included into the practice of foreign language teaching. Rapid language processing also depends on the fact whether the students are aware of the information they are speaking about.

Effective speaking implies effective listening and interacting with other participants. Skillful speakers should be conscious and take into account other opponents' feelings, their linguistic skills and professional awareness of the subject. They should realize how to take turns, allow others to do so and convey the meaning of the utterance even if some misunderstanding occurs. Communication can be considered as effective if the information sent is processed at the moment of its reception. Infor-mation processing depends mostly on the speakers' spe-cial knowledge of the topic discussed. Consequently lan-guage 
and special content teaching and learning are inte-grated in practice [12].

Conclusion. The use of Content and Language Integrated Learning is considered a new pattern in language and subject teaching as for integrating both parts (linguistic and factual) into teaching. Next, it responds to the needs of globalization and uses lingua franca as a means of communication within multinational communities. The practical employment of this teaching approach is expected, although it is quite demanding for the participating learners and teachers. CLIL emphasizes effective learning outcomes, cognitive knowledge, critical thinking, and real life use of a language in the subject's back-ground. Learners acquire the basic structures for commu-nication in a foreign language which is being developed.

The main conclusion to be drawn is the CLIL ap-proach is very effective in teaching foreign languages and developing professional skills of the students at higher educational institutions. This approach diversifies teaching tools and forms of classroom teaching and learning and consequently increases learners' motivation. The integration of foreign language teaching and professional skills development should be further investigated and widely used in teaching practice.

\section{REFERENCES}

1. Atabekova A.A., Belenkova N.M. (2013). Adaptatsiya studentov $\mathrm{k}$ mul'tikul'turnoy obrazovatel'noysrede VUZa. - Saarbrücken, Deutschland, Lambert Academic Publishing, 2013. (in Russian)

2. Belenkova N (2012). E-learning and Teaching English as a Foreign Language at University // Journal of International Scientific Publications: Educational Alternatives 2012 Vol. 10, part 2 pp. 42-49. URL: http://www.scientificpublications.net/download/educational-alternatives-20122.pdf. (in Russian)

3. Druzhinina M. V. (2008). Ponyatiye i printsipy formirovaniya yazykovoy obrazovatel'noy politiki universiteta // Izvestiya RGPU im. A.I. Gertsena. - 2008. - № 52. - S. 60-70. (in Russian)

4. Arnó-Macià, E., \& Mancho-Barés, G. (2015). The role of content and language in content and language integrated learning (CLIL) at university: Challenges and implications for ESP. English for Specific Purposes, 37, 63-73. http://dx.doi.org/10.1016/j.esp.2014.06.007

5. Banegas, D. L. (2012). CLIL teacher development: Challenges and experiences. Latin American Journal of Content and Language Integrated Learning, 5(1), 46-56 http://dx.doi.org/10.5294/laclil.2012.5.1.4

6. Bertaux, P. et al. The CLIL teacher's competences grid [online]. Available http://lendtrento.eu/convegno/files/mehisto.pdf
7. Commission of The European Communities Promoting Language Learning and Linguistic Diversity: An Action Plan 2004-2006. - Brussel, 2003.

8. Common European Framework of Reference for Languages: Learning, teaching, assessment.-Cambridge, 2004.

9. Coyle, D., Hood, P., \& Marsh, D. (2010). CLIL: Content and language integrated learning. Cambridge, UK: Cambridge University Press.

10. Eurydice. (2006). Content and language integrated learning (CLIL) at school in Europe. Retrieved from: http:// bookshop.europa.eu/en/content-and-language-integratedlearn-ing-clic-at-school-in-europe-pbNCX106001/

11. Halliday, M.A.K. (1993). Towards a Language-Based Theory of Learning. Linguistics and Education 5, 93- 116.

12. Harmer J. The Practice of English Language. 3rd Edition. London, 2001.

13. McDougald, J. S. (2015). CLIL: A fresh approach to bilingual learning. Ruta Maestra, 11, 30-38. Retrieved from http://www.santillana.com. co/rutamaestra/edicion11/articles/5

14. Temirova, F., \& Westall, D. (2015). Analysis of first and foreign language use in content and language integrated learning (CLIL) classrooms. Procedia - Social and Behavioral Sciences, 178, 217-221. http://dx.doi. org/10.1016/j.sbspro.2015.03.184

15. Woźniak, M. (2013). CLIL in Pharmacy: A case of collaboration between content and language lecturers. Language Value, 5(1). http://dx.doi. org/10.6035/LanguageV.2013.5.6 